Didáctica Geográfica n ${ }^{\circ} 22,2021$, pp. 247-273

DOI: https://doi.org/10.21138/DG.629

ISSN electrónico: 2174-6451

\title{
APORTES DE LA GEOGRAFÍA A LA ENSEÑANZA DE LOS GENOCIDIOS Y A LA CONSTRUCCIÓN DE MEMORIA CO- LECTIVA $^{1}$
}

Contributions of Geography to the teaching of genocides and the CONSTRUCTION OF COLLECTIVE MEMORY

APPORTS DE LA GÉOGRAPHIE À L'ENSEIGNEMENT DES GÉNOCIDES ET À LA CONSTRUCTION DE LA MÉMOIRE COLLECTIVE

\section{María Cristina Nin}

Departamento e Instituto de Geografía, Facultad de Ciencias Humanas, Universidad Nacional de La Pampa, Argentina

ninmcristina@gmail.com

Recibido: 24/05/2021

Aceptado: 08/10/2021

\section{RESUMEN:}

En este artículo se presenta una síntesis de la investigación desarrollada para la elaboración de la tesis de doctorado en Geografía. Es una investigación educativa que pretende realizar aportes al campo de conocimiento de la didáctica de la geografía. Se indaga el lugar que ocupa la enseñanza del concepto de genocidio y las implicancias

${ }^{1}$ Este artículo forma parte de la investigación realizada para la Tesis de Doctorado en Geografía titulada: Geografía y Genocidios. Aportes de la Geografía a la enseñanza de procesos traumáticos y el ejercicio de la memoria. Dirigida por la Dra. María Amalia Lorda y Co-dirigida por la Dra. Stella Maris Shmite. Universidad Nacional del Sur (Argentina). 
territoriales de este proceso y, por consiguiente, el rol de la enseñanza de la geografía en la construcción de memoria colectiva. Se pretende transitar un camino de diálogo entre problemas relevantes desde la perspectiva de los derechos humanos, la producción de la Geografía académica y la Geografía escolar.

\section{Palabras Clave:}

Geografía; enseñanza; investigación; genocidios; memoria.

\section{Abstract:}

This article presents a summary of the research work developed to accomplish the Doctoral Thesis in Geography. It is an educational research work, which aims at making contributions to the field of knowledge of the didactics of Geography. The role of teaching the concept of genocide and the territorial implications of such process are explored and, consequently, the role of teaching Geography in the construction of collective memory. An attempt is made to follow a path of dialogue among the relevant issues from the human rights perspective, the production of academic Geography and school Geography.

\section{KEYWORDS:}

Geography; teaching; research; genocides; memory.

\section{RESUMÉ:}

Cet article présente une synthèse des recherches développées pour la préparation de la thèse de doctorat en géographie. C'est une recherche pédagogique qui vise à apporter des contributions au domaine de la connaissance de la didactique de la géographie. La place qu'occupe l'enseignement de la notion de génocide et les implications territoriales de ce processus et, par conséquent, le rôle de l'enseignement de la géographie dans la construction de la mémoire collective est étudiée. Il vise à parcourir un chemin de dialogue entre les problèmes pertinents du point de vue des droits de l'homme, la production de géographie académique et la géographie scolaire.

\section{MoTS-CLÉS:}

Géographie; enseignement; enquête; génocides; Mémoire. 
Aportes de la Geografía a la enseñanza de los genocidios y a la construcción de memoria...

Como no es seguro que esa memoria del universo exista, necesitamos transmitir a nuestros estudiantes, a todos los jóvenes investigadores, la urgencia de recoger esos recuerdos, de hacer historia oral del mundo contemporáneo, de aplicar métodos antropológicos en la conservación de la memoria del pasado reciente. Un pasado que está cambiando profundamente ante nuestra misma mirada Capel, H. (2002, p. 67).

\section{INTRODUCCIÓN}

Las Ciencias Sociales y la Geografía, ya sea desde la investigación y la enseñanza han experimentado un giro hacia la perspectiva en derechos humanos y por lo tanto esta mirada se incluye en el currículum. De este modo, se estimulan los valores ciudadanos y la formación para la vida democrática a partir del trabajo en torno al respeto a la vida, la libertad, la justicia, la solidaridad, la honestidad, la convivencia pacífica y la responsabilidad ciudadana, entre otros. La Universidad es la institución que impulsa la enseñanza de los derechos humanos, dado que en el proceso de enseñanza y aprendizaje se piensa, se cuestiona, se crea conocimiento, y fundamentalmente, es el espacio educativo que puede y debe generar cambios en la configuración de los valores. En esta línea de pensamiento, Humberto Eco expresa que la "universidad es aún el lugar en el que son posibles los debates y las discusiones, mejores ideas para un mejor mundo, la amplificación y la defensa de los valores fundacionales de carácter universales (...)" (Eco, 2015, p. 32). Las instituciones de enseñanza superior pueden contribuir de diferentes formas a la educación para los derechos humanos, la paz y la democracia. Es por ello que resulta pertinente la investigación acerca de problemas de enseñanza que contemplen la paz, los derechos humanos, la justicia, la democracia, el ejercicio pleno de la ciudadanía y la responsabilidad social.

El siglo XX se caracterizó por ser uno de los más crueles de la historia de la humanidad, dado que está marcado por dos guerras mundiales y genocidios desarrollados en distintos territorios. Por otra parte, también se destaca por una fructífera producción científica que, desde distintas perspectivas teóricas, abordan los escenarios de violencia y no respeto por la vida. Esta dicotomía es la que nos compromete como docentes a instalar el debate en torno a la tensión que se produce en relación a los avances de la ciencia y la producción intelectual versus la destrucción de la vida humana. Explorar en la contradicción mencionada se convierte en una responsabilidad de los formadores de profesores.

En Argentina, los trabajos acerca de la memoria de Dussel (2001), Jelin (2002), Siede (2007), Varela (2009) y Rosemberg y Kovacic (2010) aportan nuevas miradas a la construcción de ciudadanía. La memoria fue y es un contenido relevante en la educación 
de los jóvenes. Enseñar la memoria posibilita comprender el pasado y proyectarse como ciudadanos hacia el futuro, es decir, establecer contacto entre las generaciones. El eje clave de la transmisión de la memoria es el dolor humano transformado en trauma histórico. Dussel expresa que esta transmisión “(...) comparte los dilemas de toda transmisión cultural y de toda acción pedagógica, sus paradojas éticas y sus encrucijadas políticas (...)" (2001, p. 67). Pensar la enseñanza con el propósito de facilitar el encuentro de nuestros alumnos con el pasado contribuye a "(...) hacernos cargo de la responsabilidad que tenemos, como parte de la sociedad en que vivimos, de transformar los dolores del pasado en esperanzas sobre el futuro" (Dussel, 2001, p. 96). Se define como memoria, "(...) al conjunto de representaciones del pasado que un grupo produce, conserva, elabora y transmite a través de la interacción entre sus miembros" (Rosemberg y Kovacic, 2010, p. 11). Es decir que la memoria colectiva se construye y por lo tanto las aulas son el espacio propicio para debatir las tensiones, luchas y conflictos de dichos procesos.

La enseñanza enmarcada en una educación en derechos humanos se corresponde con el paradigma de la pedagogía crítica. Es decir, es preciso formar en el diálogo y la reflexividad de la realidad con la que interactúan los sujetos. En este sentido Kemmis (1993) afirma respecto de la ciencia crítica que para cambiar la educación, para comprenderla e interpretarla es necesario un proceso de transformación. Por su parte Giroux (1990) reflexiona acerca del rol de los profesores como intelectuales transformadores contra las diferentes formas de opresión de la sociedad. Es decir, el trabajo de los docentes articula la reflexión y la acción con el propósito de potenciar las habilidades y conocimientos de los estudiantes para que puedan intervenir en las injusticias como actores críticos. Desde esta perspectiva, la educación contribuye al empoderamiento social, es decir, al cambio personal y social, favorece a formar sujetos activos, cooperativos y socialmente comprometidos. La enseñanza del concepto de genocidio y sus implicancias, contribuirá a estimular en los estudiantes una conciencia ciudadana y posibilitará reconocerse como sujetos activos de la realidad caracterizada por tensiones y conflictos.

Esta investigación se plantea indagar el lugar que ocupa la enseñanza del concepto genocidio y las implicancias territoriales de este proceso y, por consiguiente, el rol de la enseñanza de la Geografía en la construcción de memoria. Se parte de la idea acerca de la relevancia de enseñar a partir de conceptos clave que permite sostener, a lo largo de una secuencia de enseñanza, la presencia de un eje transversal que constituye la llave para provocar aprendizajes relevantes y significativos. Éstos podrán contribuir a que los estudiantes interpreten la vida social con sus valores y contradicciones así como también, los contextos territoriales que la explican. Resulta pertinente considerar la dimensión ética de la Geografía crítica (Ortega Valcárcel, 2004), la que supone reivindicar valores sustantivos en relación a las personas, la igualdad, la libertad individual y social, el derecho a condiciones de vida y relaciones sociales no discriminativas ni nocivas. La 
promoción de la libertad, la dignidad, el respeto por los otros diferentes se constituyen en pilares de una Geografía que se utilice para resolver problemas sociales a partir del diálogo y la convivencia de opiniones diversas.

Indagar los aportes teóricos y las producciones académicas que conforman las explicaciones acerca de este concepto; las propuestas de los diseños curriculares y la interpretación que los docentes realizan de éstos se constituye en el problema clave. En síntesis, los genocidios ocurridos en el siglo $\mathrm{XX} \mathrm{y} \mathrm{XXI}^{2}$ son un problema territorial y por lo tanto, compromete a los investigadores geógrafos y a profesores/as a abordarlos desde una perspectiva multidimensional.

\section{METODOLOGÍA}

La investigación en Didáctica de la Geografía es un campo complejo de la investigación educativa debido a que necesariamente se nutre de diversas disciplinas sociales y además presume “(...) la articulación de un conjunto de decisiones epistemológicas, políticas y pedagógicas" (Fernández Caso y Gurevich, 2014, p. 17). Uno de los propósitos de esta línea de indagación es contribuir al debate para mejorar las prácticas de enseñanza en todos los niveles educativos. Esto requiere una necesaria articulación entre los ámbitos donde se producen las investigaciones y los que se dedican a las prácticas de enseñanza, tales como escuelas de nivel inicial, primario y secundario, institutos y la universidad. $\mathrm{Si}$ bien los procesos de cambios culturales, las transformaciones curriculares y sociopolíticas influyen en la enseñanza; son los profesores los que se convierten en los agentes de la innovación en la enseñanza (Fernández Caso y Gurevich, 2014). La relación entre el conocimiento y los procesos de enseñanzas y de aprendizajes, fue y es el motivo de la investigación en didáctica general, cuando ese conocimiento se trata de un área específica, en este caso la Geografía, resulta pertinente revisar algunas consideraciones acerca de éste área de estudio.

La Didáctica de las Ciencias Sociales como campo de conocimiento científico se desarrolló en las últimas tres décadas gracias al crecimiento de las investigaciones y su divulgación en ámbitos académicos de Universidades de Europa, Estados Unidos y

2 El recorte temático selecciona casos que se consideran significativos para cumplir con el propósito de dar a conocer temas escasamente trabajados en propuestas de enseñanza. La exclusión de la tesis de otros casos tales como el Holocausto judío, el genocidio de Camboya, el de Sudán, el Apartheid en Sudáfrica, el genocidio de los indígenas en América, los desaparecidos de las dictaduras de América Latina no implica de modo alguno su negación. Por el contrario, visibilizar otros genocidios aportará elementos comparativos para desarrollar en futuras investigaciones y en la enseñanza de una geografía comprometida con los derechos de todos los ciudadanos del mundo. 
América Latina. Como disciplina científica cuyo objeto de estudio son los procesos de enseñanza y aprendizaje de las ciencias sociales y la formación del profesorado, establece vinculaciones entre los conocimientos y las teorías de las ciencias de referencia, con las ciencias de la educación (Camilloni, 1996; Benejam, 1999, 2001). Las investigaciones que de esta derivan contribuyen a la formación de profesores preocupados por la enseñanza y el aprendizaje de conocimientos de las ciencias sociales y enriquecen los debates en los ámbitos de investigación.

Tal como expresan González Valencia y Santisteban Fernández (2014, p. 7-8), “(...) es fundamental que los investigadores y profesores conozcan las disciplinas de referencia, y tengan conocimientos de la manera sobre cómo trasladar sus teorías y herramientas a la enseñanza y aprendizaje, para llegar a desarrollar pensamiento social". El conocimiento científico en el área de la didáctica de las ciencias sociales, y también de la Geografía es aquel que se ha conseguido mediante un camino metodológico que permite elaborar explicaciones racionales y rigurosas de los procesos sociales que se enseñan. En este sentido, Prats (2002) sostiene que el camino metodológico es el que posibilita concebir una práctica investigadora en didácticas específicas, debido que es a través de él que se delimitan "(...) los saberes didácticos obtenidos por la práctica profesional (y que forman parte de una cultura didáctica), del conocimiento obtenido a través de la investigación" (Prats, 2002, p. 84). La construcción de un campo específico de investigación en didáctica de la Geografía deriva de los procesos de reflexión que profesores de diferentes latitudes han realizado y debatido en las últimas décadas. Las prácticas en la investigación en relación dialéctica con las reflexiones teóricas están construyendo un corpus de metodología de investigación en esta área.

Entre las líneas y enfoques de investigación en Didáctica de las Ciencias Sociales, Estepa Giménez (2009), Levstik y Tyson (2008), así como Henríquez y Pagés (2004), distinguen las siguientes: a) las relacionadas con el curriculum; b) las centradas en las tareas de los profesores; c) las que focalizan en los aprendizajes de los estudiantes; d) las que hacen hincapié en las interacciones entre el profesor, el alumno y el curriculum, es decir, sobre enseñanza y aprendizaje; y por último, e) las que indagan en aspectos de epistemología y metodología de investigación. Por otra parte, Hernández Cardona (2000) delimita dos líneas de investigación: una básica, centrada en los objetos de estudio históricos, geográficos o sociales con la intención de crear modelos sobre ellos; y otra aplicada, que consiste en el análisis de las múltiples variables que intervienen en el desarrollo del tratamiento didáctico del objeto de estudio. Este trabajo articula las que analizan cuestiones curriculares y las prácticas de los profesores, priorizando la articulación dialéctica entre ambas. Se puede afirmar que es una investigación aplicada ya que contempla en su camino metodológico, la compleja trama de conceptos, ideas, perspectivas educativas y miradas geográficas sobre el objeto de estudio. 
Desde la mirada didáctica, el territorio de los profesores de Geografía es, sin dudas, el aula, en palabras de investigador francés Thémines (2009), este terreno concentra implicaciones importantes para la investigación y la formación. Como estrategia de investigación en formación, la del terreno del aula es la única que permite observar y comprender las prácticas. La Didáctica de la Geografía se convierte de este modo, en un campo propicio para construir la consolidación de la ciencia en la producción de investigaciones que aporten conocimientos a los profesores porque éstos son responsables de la enseñanza de la mirada socio-territorial de la realidad. Por su parte, contribuyen, con sus conocimientos a formar ciudadanos críticos, desde la perspectiva de las Ciencias Sociales.

Son los profesores los que promueven los procesos de innovación en la enseñanza, por lo tanto, también estimulan cambios culturales y son los hacedores de la implementación de las propuestas curriculares. En contextos de crisis social e incertidumbres, orientar la enseñanza de la Geografía como ciencia explicativa e interpretativa requiere de la actitud crítica y reflexiva del docente, que favorezca la selección y secuenciación de saberes fundamentados desde posturas epistemológicas, que movilicen el pensamiento crítico y autónomo. La relación entre experiencias de investigación y prácticas de enseñanza, fortalece la puesta en marcha de un proceso de reflexión en tanto se puedan desarrollar instancias de planificación, acción y reflexión de éstas prácticas. Bucear en la dialéctica teoría - práctica, a partir del interés por la investigación en problemas didácticos orienta el análisis e interpretación de las prácticas de enseñanza y enriquece los procesos de reflexión colectiva.

Esta investigación pretende contribuir a la elaboración de reflexiones sobre los conocimientos enseñados y sobre las prácticas de enseñanza desde el enfoque de la didáctica específica para revalorizar lo disciplinar en la enseñanza. Tutiaux-Guillon (2003) basándose en la propuesta de Chervel, expresa que la disciplina escolar se encuentra dirigida por las finalidades que la sociedad reconoce en ella y que le otorga cada institución educativa. Las disciplinas escolares presentan componentes que deben funcionar en articulación e interacción con las finalidades; con los contenidos que la sociedad espera que se enseñen (denominados vulgata por Chervel); con las prácticas relacionadas con el estudio; con la comunicación entre docentes y alumnos y por último, con los procedimientos evaluativos (Tutiaux-Guillon, 2003).

Según este enfoque las prácticas de enseñanza se basan en seleccionar conocimientos y además, construirlos, es decir que el docente se convierte en el hacedor de la construcción de los saberes socialmente relevantes. En este sentido, el camino metodológico de la investigación articula las propuestas institucionales (Programa "Educación y Memoria" y los materiales curriculares) y el rol de los docentes en Geografía (selección de contenidos, estrategias pedagógicas) al momento de materializar en el aula prácticas 
de enseñanza en relación con los genocidios del siglo XX, desde la perspectiva de los derechos humanos, como acciones constructoras de memoria colectiva.

Es una investigación en Didáctica de la Geografía, responde a los postulados de una investigación mixta, debido a la complejidad del objeto de estudio que requiere una tarea analítica de fuentes bibliográficas que permitan establecer bases teóricas, y contribuyan a explicar la realidad y actualidad de los genocidios y su enseñanza. Además la tarea investigativa requiere del trabajo de campo para indagar las prácticas de enseñanza de las problemáticas planteadas. Para ello, las fuentes primarias se recopilan a partir de entrevistas en profundidad a profesoras/es de nivel secundario. Los datos se contextualizan situándose en una perspectiva interpretativa debido a que se intenta comprender la conducta humana a partir de los significados de los sujetos que intervienen en el hecho educativo (Bolívar, 2002).

Se realiza el análisis de los materiales curriculares nacionales y provinciales de la educación secundaria. La interpretación de dichos materiales se retroalimenta con entrevistas a profesores de enseñanza secundaria e informantes clave del sistema educativo. Analizar las prácticas de enseñanza es promover espacios de reflexión que posibiliten construir nuevas hipótesis, realizar diferentes interpretaciones y elaborar nuevos aportes teóricos. La investigación pretende que la teoría y la práctica dialoguen de manera permanente (Latorre, 2003). El universo de estudio está constituido por profesores de cuarto año de la educación secundaria de la ciudad de Santa Rosa y los agentes del Estado que trabajaron y/o trabajan en los diseños curriculares de la provincia de La Pampa. La unidad de análisis es individual (los profesores y los agentes del Estado que participan y/o participaron de los diseños curriculares vigentes).

El recorte temporal comprende desde el período de creación de los Núcleos de Aprendizajes Prioritarios (2004) hasta la actualidad. Dicho recorte temporal se corresponde con una etapa de profundos cambios desde el punto de vista curricular y por lo tanto, las repercusiones en la enseñanza constituyen un campo a explorar en el campo de la Didáctica de la Geografía. El plan de tareas consistió en: analizar los materiales curriculares nacionales y provinciales; interpretar los Programas Educativos Nacionales vinculados a la temática de investigación; entrevistar a los diferentes actores seleccionados y analizar sus narrativas según su grado de responsabilidad en la enseñanza; interpretar la documentación académica (libros y artículos de revistas científicas) y la documentación de divulgación (periódicos, literatura, páginas web).

Souto González (2013) expresa que investigar en educación refiere al proceso de reflexión de búsqueda sistemática a través de actividades intencionales para descubrir e intervenir en algo nuevo, esta intervención contribuiría a influir en la práctica del aula para mejorarla. En este sentido, se pretende transitar un camino de diálogo entre los problemas relevantes desde la perspectiva de los derechos humanos, la producción de la Geografía 
Aportes de la Geografía a la enseñanza de los genocidios y a la construcción de memoria...

académica y la Geografía escolar. Se aspira a contribuir a la profesionalización de la tarea docente ya que, y en coincidencia con Le Roux (2005), uno de los propósitos de la profesionalización docente es el saber, el tener conocimientos empíricos relacionados con los conocimientos científicos. Investigar en el área de la Didáctica de la Geografía con el propósito de producir nuevos conocimientos permitirá legitimar y lograr reconocimiento académico en la formación de profesores-investigadores.

\section{EL ABORDAJE DE LOS GENOCIDIOS DEL SIGLO XX Y XXI DESDE UNA PERSPECTIVA GEOGRÁFICA}

El análisis de los procesos genocidas, a partir de estudios de algunos casos seleccionados tiene como propósito dar a conocer procesos traumáticos y ponerlos a consideración de la comunidad académica y educativa. Las tramas conflictivas muy complejas que afectaron y, aún hoy continúan provocando daños materiales y sociales a gran cantidad de seres humanos en diversos territorios y la ruptura de las territorialidades construidas socialmente es una de las consecuencias de los genocidios y habilita el estudio en clave territorial. Así mismo, es posible aplicar en la comprensión de los procesos genocidas los rasgos aportados por Oslender (2018) en lo que denomina las geografías del terror, dado que todas son acciones de los individuos que se transforman en estrategias sociales territorializadas. Planificar la enseñanza de problemas sociales relevantes y controvertidos como el que se selecciona para este trabajo, se sustenta en la perspectiva de la teoría crítica y en los estudios sociales críticos. Es decir, pensar en una educación geográfica para “(...) la justicia social, que contemple problemas sociales, que cuestione el poder y las situaciones de desigualdad y las injusticias" (Santisteban Fernández, 2019, p. 63). De este modo las cuestiones socialmente vivas, según la denominación de investigadores francófonos, tales como los reclamos de minorías silenciadas, discriminadas en el pasado o en el presente se convierten en temas de debate en la sociedad y por lo tanto es responsabilidad de los educadores que estén presentes en las aulas. En este sentido, "A los grupos ya reconocidos, como los portadores de las memorias de los genocidios, se han añadido aquellos que reivindican la memoria de la esclavitud, la trata de esclavos y del sufrimiento de la colonización" (Santisteban Fernández, 2019, p. 66). La enseñanza de la Geografía para la construcción de ciudadanía implica compartir responsabilidades tal como se plantea en la Agenda 2030 que presenta ONU, la propuesta de UNESCO de Educación para la Ciudadanía Mundial, los principios de la Unión Geográfica Internacional, los diseños curriculares de los Ministerios de Educación de cada Estado y de cada Provincia y el compromiso de cada docente contribuyen a la construcción de una sociedad más justa y equitativa.

El siglo XX ha dejado valiosos avances en materia de derechos, tales como la Declaración Universal de Derechos Humanos y la Convención para la Prevención 
y Sanción de los Genocidios. Ambas constituyen un intento de diferentes actores sociales: investigadores, instituciones estatales, internacionales, activistas e integrantes de variadas Organizaciones No Gubernamentales (ONG) de reflexionar y poner fin a crímenes cometidos durante siglos. El marco legal que propone prevenir y castigar las atrocidades cometidas no es suficiente si se tienen en cuenta los conflictos bélicos que aún persisten y los nuevos que surgen. El Legado de Stéphane Hessel (2011) a través de su lucha y sus escritos, compromete a los integrantes del ámbito educativo, tanto desde la investigación como de la enseñanza a trabajar desde la perspectiva de los derechos, la resolución de los conflictos, la promoción del diálogo y el respeto por la diversidad como único camino para construir una sociedad democrática.

En la Figura $\mathrm{N}^{\circ} 1$ se representan las distintas masacres ocurridas en el mundo durante el siglo XX. Las causas y consecuencias son diversas y todos los casos merecen un abordaje en profundidad. En la investigación que se sintetiza en el presente artículo se seleccionan los casos de Hereros y Namas (Namibia), Armenios (Imperio Otomano) y Tutsis y Hutus en Ruanda.

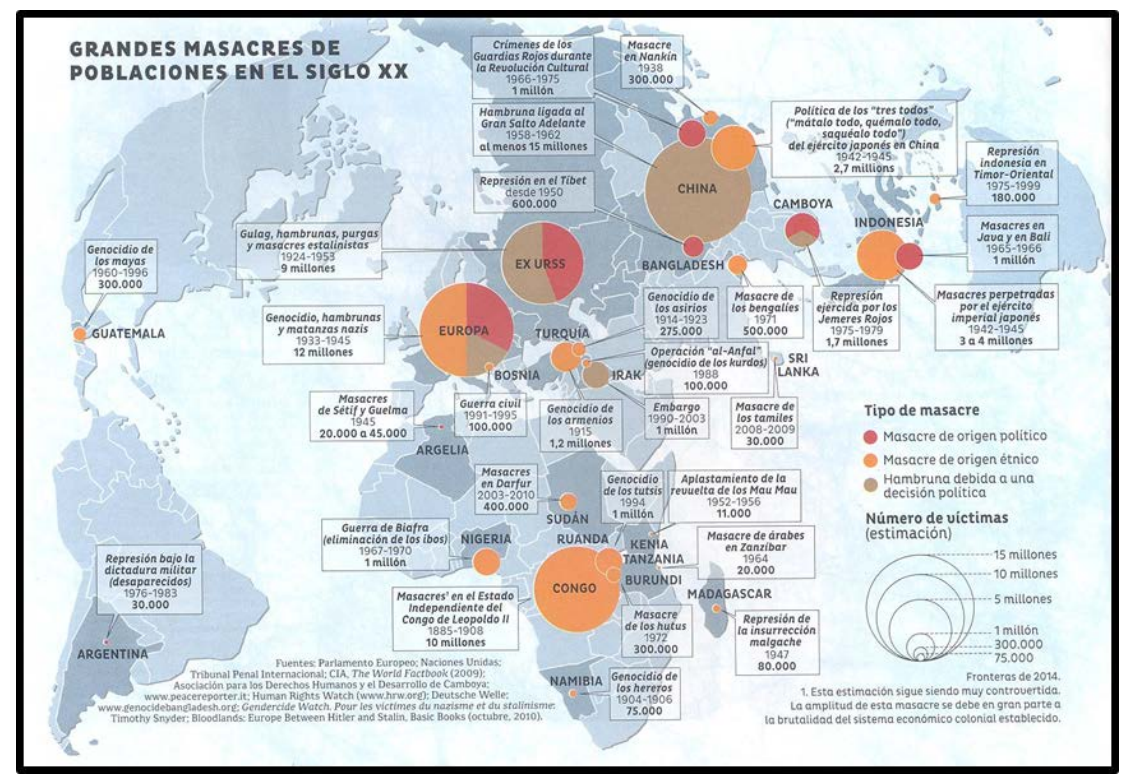

FiguRa 1. Cartografía de los genocidios del siglo XX. Fuente: Bréville, B. (2016, pp. 76)

El contexto jurídico y político actual a escala internacional, posibilita la recuperación de los reclamos legales respecto a genocidios tal como el cometido contra los Hereros y Namas, ocurridos en Namibia a principios de siglo XX. Las acciones que lleven a cabo los 
Aportes de la Geografía a la enseñanza de los genocidios y a la construcción de memoria...

actores internos, los gobiernos de Namibia y Alemania, y organizaciones internacionales tanto políticas como académicas, construirán en el futuro la reparación por los derechos humanos de los pueblos afectados. El caso de los Hereros y Namas se visibilizó en los periódicos internacionales en el año 2017, si bien investigadores de diferentes países trabajan desde hace años en el tema, decisiones como el Museo del Holocausto de París de preparar una muestra especial para dar a conocer fuentes fotográficas, fílmicas y documentales del genocidio de los Hereros y Namas puso en tensión los reclamos ante la comunidad internacional. El presente abre la posibilidad de poner en discusión en la comunidad internacional temáticas que parecían olvidadas.

Por su parte en 2015, año en que se conmemoró el centenario del genocidio Armenio, permitió a los docentes comprometidos con la defensa de los derechos humanos instalar en las aulas su análisis y discusión. El genocidio de los Armenios perpetrado a principios del siglo XX se explica a partir de la articulación de los acontecimientos mundiales y los ocurridos en Medio Oriente construyeron una trama geopolítica de poderes desiguales que perjudicó a la identidad de un pueblo. En la madrugada del 24 de abril de 1915 comienza el proceso de genocidio con la detención y asesinato de intelectuales, religiosos, maestros, artistas, escritores. Este proceso es parte de lo que Varela (2009) denomina Aghed, la catástrofe o el desastre, que incluye las masacres previas a 1915, deportaciones masivas, asesinatos de mujeres y niños así como el genocidio cultural. La población Armenia fue la avasallada en este episodio dramático de la historia. La dispersión de ciudadanos armenios por diferentes latitudes y especialmente en Argentina, conformó una diáspora que asumió el compromiso de luchar para dar a conocer sus traumas y para escribir en las páginas de la historia del siglo XX su legado. Pensar en clave geohistórica el genocidio y las etapas sucesivas que sitúan a este proceso en el centro del reclamo por su reconocimiento a nivel mundial es una tarea que la investigación y la docencia tiene la responsabilidad de debatir.

En relación con el genocidio de Hutus y Tutsis en Ruanda, si bien es investigado y existen numerosas publicaciones, se considera que la enseñanza secundaria tiene una deuda educativa con lo acontecido en el "país de las mil colinas". El camino político en la lucha para el resarcimiento de las víctimas es reciente. Según Bruneteau (2006) el genocidio en Ruanda presenta algunas características que lo distinguen de otros ocurridos en el siglo XX. Entre ellas, la dimensión masiva ya que la tasa de desaparición de la población Tutsi fue del 80 \%; la rapidez de su ejecución debido a que en solo tres meses murieron aproximadamente 800.000 personas; la crueldad de los métodos de exterminio utilizados; la violación sistemática y a gran escala, se registraron 250.000 denuncias de abusos; y por la organización descentralizada , es decir la microgestión en las distintas regiones permitió que todo el territorio presentara asesinos armados con machetes. Además del Ejército, la gendarmería y las milicias, miles de ciudadanos se 
convirtieron en agentes del genocidio. En síntesis las responsabilidades son compartidas entre varios actores sociales, políticos, religiosos, nacionales e internacionales. Los grupos radicalizados Hutu, la comunidad internacional africana y no africana (Bélgica, Francia, Estados Unidos, la ONU); los medios de comunicación como la radio Televisión Libre des Miles Colines quien difundía propaganda antitutsi y la Iglesia que por omisión o silencio no intervino de manera positiva (Wabgou, 2013).

La polarización entre las dos etnias principales creció desde el período de la colonización, la construcción de un ellos y un nosotros (víctimas inocentes) alimentó la idea de un "otro" responsable de los males que sufría la sociedad. Esa amenaza estaba representada por los Tutsis, quienes se constituían como el enemigo. La ciudadanía participó de las masacres, y acató esta decisión de someterse a las órdenes de la autoridad. De este modo, la población se debilitó a través de la sumisión y en cierta manera se sentían absueltos de responsabilidad, "Para los que llevaban las riendas, la complicidad de las masas podía ser su mejor defensa. Así el grado de participación popular representaba una táctica de supervivencia para todos los genocidas" (Leach, 2003, p.340).

Las rivalidades étnicas entre Tutsis y Hutus en Ruanda no constituyen la causa que explica el genocidio ocurrido en la década de 1990 en el país africano. El contexto de diferencias o tensiones históricas existentes entre ambos grupos fueron la excusa para que el poder gobernante sembrara el odio necesario para desencadenar la masacre. La guerra civil acontecida en décadas previas construyó los antecedentes para desencadenar el genocidio perpetrado en solo cien días. El análisis del rol que desempeñaron los diferentes actores tanto nacionales como internacionales legitimaron las acciones del grupo Hutu, en ese entonces, el que gobernaba.

Si bien hoy se considera a Ruanda un país próspero desde la mirada económica, las heridas aún son muy recientes. Los sobrevivientes de los cien días de violencia extrema, permiten, a través de sus testimonios el acercamiento a su traumático pasado. El paisaje ruandés tiene plasmado los vestigios de la crueldad y la geografía del país de las mil colinas nos convoca a observar, analizar e interpretar las huellas territoriales.

\subsection{Los procesos genocidas, siguen vigentes}

A diferencia de los anteriores genocidios, hoy la comunidad internacional observa los hechos traumáticos en tiempo real, o al menos tiene la posibilidad de hacerlo. Las escenas de horror se transmiten de manera directa debido a las ventajas de las tecnologías de comunicación actuales. Persecución y matanzas de rohingyas en Myanmar, uigures en China, yazidíes en Irak, conflictos bélicos que se prolongan en el tiempo con 
consecuencias humanitarias ${ }^{3}$ inéditas tales como el de Sudán, República Democrática del Congo, República Centroafricana, el conflicto árabe israelí. El conocimiento de los hechos se produce de manera simultánea a su desarrollo, independientemente de los territorios donde ocurran e interpelan a la comunidad educativa para difundir estos hechos y buscar materiales de lectura serios y transformarlos en propuestas pedagógicas. Por un lado, desde el nivel universitario, para investigar y publicar documentos científicos que se conviertan en materiales de consulta para los profesores de colegios secundarios. Los profesores, como constructores de curriculum, tienen la responsabilidad de capacitarse, informarse y buscar estrategias para enseñar acontecimientos en desarrollo y que ocurren en territorios en diferentes escalas.

\section{LAS POLÍTICAS EDUCATIVAS Y LAS PRÁCTICAS PEDAGÓGICAS. LA DIALÉCTICA ENTRE LA GESTIÓN Y LA DOCENCIA}

Desde una mirada multiescalar sobre las políticas de memoria en relación a la educación, se considera a la memoria como contenido a enseñar y para fomentar el diálogo con los jóvenes del presente y las generaciones futuras. Debido a que, "No podemos asegurar que no haya nuevas catástrofes en el futuro; de hecho, son probables si nuestro modelo de civilización no se modifica, pero las tentativas de cambiar el mundo que se hicieron en el pasado han fracasado. Hay que cambiar de ruta y no tenemos brújula" (Traverso, 2016, p. 70). En este sentido, se destaca el rol de la enseñanza para conocer y comprender las problemáticas de territorios lejanos con la finalidad de desarrollar vínculos cognitivos y emocionales con los sujetos que forman parte de ellos. A partir del año 2006 con la sanción de la Ley de Educación Nacional se favorecen las condiciones normativas y de investigación y producción académica, para fomentar desde la enseñanza la construcción de memoria. Asimismo, se promueven capacitaciones docentes y producción de materiales para docentes y estudiantes de los distintos niveles educativos.

En relación a las capacitaciones los docentes expresan la ventaja de la existencia de capacitaciones de forma online a través del Programa Nacional de Formación Permanente "Nuestra Escuela". Por otra parte se destaca el rol de las instituciones educativas en la promoción y difusión de la información respecto a las capacitaciones. Sin embargo la mayor dificultad que los/as profesores/as identifican es la de trabajar en equipos interdisciplinarios, es decir la posibilidad de elaborar proyectos que articulen los saberes de diversas materias a modo de Aprendizaje Basado en Proyectos debido a la organización de los horarios escolares y la fragmentación de sus trabajo en varias

\footnotetext{
${ }^{3}$ Los conflictos que persisten en el tiempo y que presentan consecuencias humanitarias tales como gran cantidad de muertes, desplazamientos forzosos, pérdida de identidad, pueden considerarse genocidios lentos.
} 
instituciones. Algunos de los docentes reconocen como ámbito de formación continua, además de las propuestas ministeriales, las capacitaciones en el ámbito de la Universidad.

La planificación e implementación de un Programa educativo requiere de un compromiso colectivo para que esta política de Estado tenga impacto en las prácticas pedagógicas. A partir de estas ideas cabe preguntarse ¿cuán significativo y relevante es la enseñanza de los genocidios ocurridos en el siglo XX y XXI? ¿Estarán los adolescentes, estudiantes de secundaria, interesados en abordar crueldades de la naturaleza de las ocurridas en contextos genocidas? Es en este punto donde el docente cumple un rol relevante en la planificación de la enseñanza. Despertar el interés por temáticas desde la perspectiva de los derechos humanos para que puedan pensarse ellos mismos como sujetos de derecho, es uno de los ejes vertebradores de la formación en ciudadanía. Formar a los estudiantes en el conocimiento geográfico les brindará habilidades para interpretar y comprender problemáticas que afectan a la sociedad y de este modo, poder decidir actuar y convertirse en actores sociales activos para intentar intervenir en ellas.

En la investigación se pudo interpretar que no obstante los avances en materia de derechos, de políticas públicas de protección persisten diferentes violencias tales como la violencia sexual en contextos de conflictos armados. Esta práctica continúa desarrollándose en diferentes territorios y provoca desplazamientos forzados, daños físicos y psicológicos irreparables. Las consecuencias avanzan hacia la exclusión de comunidades de sus tierras, el desarraigo, la ruptura de la trama social, la humillación de mujeres, hombres, niños y niñas. Los actuales conflictos ${ }^{4}$ activos en diferentes continentes han registrado utilización de violencia sexual. Son ejemplos de ello, Irak, Myanmar, Sudán, Sudán del Sur, y la República Democrática del Congo, territorio donde la problemática continúa desde hace décadas.

Otra de las violencias que se identificó es la ejercida hacia lo/as niños/as ya que existen condiciones en algunos territorios que favorecen la permanencia de niños en conflictos bélicos debido a un recrudecimiento de las luchas armadas. La realidad de niños utilizados en conflictos continúa y es difícil de erradicar. Los mecanismos jurídicos que se crearon para abordar este tipo de prácticas que violan los derechos humanos de los niños avanzan con lentitud. Sin embargo, se considera un avance que a lo largo del siglo XX y lo que va del presente se discuta en los organismos internacionales esta problemática. Asimismo se destaca el rol de otros agentes internacionales en el trabajo de vigilancia, investigación y

${ }^{4}$ El Consejo de Seguridad de Naciones Unidas el 23 de marzo de 2018 publica el "Informe del Secretario General sobre la Violencia relacionada con los Conflictos" en el cual se expresa la preocupación por la continuidad y expansión a nuevas área de tensión de este tipo de violencia. El Informe cuenta con detalles de territorios afectados, identifica a los actores involucrados en cada caso y elabora recomendaciones para los Estados. Disponible en: https://www.refworld. org.es/pdfid/5ad4da0c4.pdf. 
Aportes de la Geografía a la enseñanza de los genocidios y a la construcción de memoria...

denuncias, tales como las Organizaciones no gubernamentales que despliegan su trabajo en el territorio y con los sujetos afectados. Los programas de rehabilitación y de reinserción social resultan insuficientes ya que siempre hay alguno de los actores involucrados que no cumple con todo lo que proponen y aún siguen existiendo reclutamientos de niños. La clave es la prevención y la finalización de las capturas de menores para estos fines.

El futuro sigue plagado de retos y desafíos en cuanto al trabajo para erradicar la violencia sexual tanto en contextos de paz como en guerras. Más bien el reto es finalizar con los conflictos armados. Los Estados, Organismos Internacionales, Instituciones educativas y de Investigación y ONG tendrán que trabajar de manera rigurosa para relevar la problemática y brindar atención a las víctimas. Luchar contra la tolerancia y la impunidad de estos crímenes es indispensable para visibilizar el fenómeno y transformarlo. La memoria histórica y la memoria del presente de las víctimas y sobrevivientes precisa de la correspondiente restauración.

Si se hace foco en qué puede aportar la Geografía a la enseñanza de la construcción de ciudadanía, es sin dudas, el ejercicio del pensamiento crítico, no solo del análisis e interpretación de la realidad, sino también desde la intervención o la elaboración de propuestas que superen o intenten superar la realidad que les toca vivir. Esta es una tarea compleja, construir conocimiento acerca de la realidad territorial contemplando múltiples dimensiones de análisis, es un desafío de la enseñanza de la Geografía para el siglo XXI.

Las consideraciones que surgen de la investigación se presentan en los siguientes ejes estructurantes que pueden ampliarse, articularse y/o adecuarse a cada realidad territorial, es decir que a partir de ellos es posible planificar propuestas pedagógicas situadas, enriquecerlas y producir conocimiento acerca de contextos poco conocidos:

Políticas de memoria y educación para la ciudadanía. La educación geográfica es indispensable para el desarrollo de ciudadanos responsables y activos en el mundo presente y futuro. La Geografía es una asignatura que informa, capacita y al mismo tiempo, estimula la comprensión del mundo otorgando posibilidades de intervenir. En este sentido, la investigación respecto a la educación geográfica se hace necesaria para profundizar en las dimensiones teórica y práctica. A partir de ellas mejorar las prácticas pedagógicas, el curriculum, la evaluación de la enseñanza y orientar nuevas investigaciones guiadas por el compromiso crítico y reflexivo. Una de las líneas tanto de investigación como de enseñanza es la que toma como eje la perspectiva de los derechos humanos y la construcción de la cultura de la paz. Trabajar en la solución no violenta de los conflictos desde el enfoque de los derechos humanos y el fomento de los principios democráticos para la formación de ciudadanía, se convierte en el desafío de los profesores comprometidos pedagógicamente con el paradigma de la inclusión. 
La propuesta se enmarca en la educación para la ciudadanía mundial. Desde este enfoque, Sant (2018) propone educar para construir ciudadanías globales, en plural, para que los estudiantes comprendan que existen distintas miradas acerca de la ciudadanía. En este sentido todas las perspectivas son igualmente válidas. Esta ciudadanía global tiene que incorporar el conflicto en sus discusiones. Es decir la búsqueda de consensos entre los intereses nacionales y globales como eje de este marco educativo. Al igual que la globalización, la ciudadanía global presenta múltiples variables, algunas son parte del sistema y permanecen mientras que otras son marginales en la trama global de relaciones. Debates, redefinición de políticas educativas, nuevas propuestas curriculares y de enseñanza es la tarea que los Estados comprometidos con la Agenda 2030 de Desarrollo Sostenible, tendrán que incorporar en las políticas públicas. La Agenda mencionada aporta lineamientos para el trabajo en pos de la construcción de ciudadanía y la igualdad de oportunidades. La educación en derechos humanos es parte de un proceso que precisa a los diferentes actores involucrados en la promoción, defensa y garantía de los mismos.

La política pública de memoria es una herramienta del Estado para garantizar la existencia y la expresión de la pluralidad de memorias que están presentes en la trama social. Es responsabilidad de los diversos actores generar las condiciones de reconocimiento de sus puntos de vista y lograr la visibilización en la escena pública.

La enseñanza de la Geografía para la construcción de ciudadanía implica compartir responsabilidades y requiere del compromiso de cada docente para construir una sociedad más justa y equitativa. La educación en derechos humanos y ciudadanía repercuten en la igualdad de oportunidades, la inclusión de sectores marginados, el respeto y cuidado del ambiente, la construcción de memoria colectiva, en síntesis, en la formación de cultura democrática.

Derecho Internacional y avances en protección de los derechos humanos. El siglo XX y la construcción del orden mundial surgido luego de la Segunda Guerra Mundial, conformó un escenario donde se desarrolló una trama de normas vinculadas con la protección de los derechos humanos a diversas escalas.

El marco jurídico internacional y las leyes de cada Estado organizan un sistema de normas jurídicas que evolucionaron conforme se reconocieron serios incumplimientos al respeto a grupos sociales y abusos de poder. Las nuevas normas del derecho internacional se convierten en instrumentos que influyen en las relaciones internacionales y de este modo, también en la organización de los territorios.

La Declaración Universal de los Derechos Humanos (DUDH) de 1948, que surgió por iniciativa de países occidentales, consolidó el nacimiento de los marcos de referencia que contemplan la dignidad humana a escala global. Los derechos humanos son conquistas históricas que implican el esfuerzo y luchas por el respeto y dignidad humana individual 
Aportes de la Geografía a la enseñanza de los genocidios y a la construcción de memoria...

y colectiva por una sociedad más libre e igualitaria. Este conjunto de valores éticos y políticos están en permanente construcción.

En este contexto, los jóvenes estudiantes como ciudadanos de pleno derecho y, por lo tanto, actores socioespaciales que tienen voz y que mediante sus acciones presentes y futuras se apropian del espacio de manera individual, social y política, se transforman en hacedores de la construcción de los derechos humanos. A partir de sus propias experiencias de vida y las relaciones sociales de las cuales son parte.

Imágenes como marcas de violencia y construcción de memoria. Las imágenes poseen la fuerza de la resistencia cuando se hacen públicas, sirven para realizar denuncias y hacer visible los hechos que de otra manera quedarían ocultos. Conceden a las víctimas una reparación simbólica por convertirse en herramienta pedagógica o por ser generadora de memoria. La fotografía y el cine conforman la cultura visual moderna, su reproducción masiva contribuyen a otorgar credibilidad a realidades complejas, reveladoras y dolorosas, tales como los procesos que se trabajan en esta tesis.

Las imágenes del horror publicadas adquieren importancia política. De este modo, los fotoperiodistas se convierten en agentes democratizadores por convertir en masivas sus publicaciones y transformarlos en testimonios visuales y narrativos. Es así como a través de su arte/trabajo construyen memoria colectiva y estimulan la participación de los ciudadanos espectadores ampliando y enriqueciendo sus perspectivas, sus miradas políticas y la creación de múltiples memorias visuales.

El investigador y el profesor tienen la posibilidad, a través del uso de imágenes, de intervenir en el presente y estimular la comprensión del pasado al proponer lecturas heterogéneas y resignificar las imágenes con sentido pedagógico.

Las imágenes, tanto fotográficas como móviles evocan el pasado y se convierten en la clave para explotar potencialidades pedagógicas y políticas con relación a la lucha por la verdad y la búsqueda de justicia. Las imágenes ponen en situación a los espectadores, los interpelan, los afectan y emocionan, se produce un diálogo en el que cada observador se convierte en participante a través de sus significaciones.

Las imágenes se convierten en marcas territoriales (Jelin y Langland, 2003) ya qu construyen una territorialidad de la memoria que posibilita a través de sus diversos modos de construir simbolismos, tales como publicaciones en periódicos, exposiciones en museos, sitios de memoria. De este modo, invitan a una acción colectiva para construir ciudzadanías democráticas. Jelin (2002) reconoce a las memorias como objetos de disputas, conflictos y luchas, en las cuales participan actores sociales con diferente grado de poder y por lo tanto, de producción de sentido. Es así como las sociedades que atravesaron procesos traumáticos sufren batallas de la memoria, es decir los sujetos reconstruyen las memorias y crean múltiples narrativas y significaciones. 
Testimonios y biografías como narrativas de la memoria. Los testimonios de vivencias traumáticas escritos en primera persona, lo que Arfuch (2014) denomina espacio biográfico, ofrecen perspectivas comprometidas, reflexivas, heterogéneas que esperan en el lector la hospitalidad de la escucha y se convierten en hacedores de memoria. Las múltiples voces invitan a dialogar con los protagonistas de traumas sociales como los sobrevivientes de los genocidios. El discurso geográfico contribuye a la interpretación desde la perspectiva del lenguaje. Estas tendencias se corresponden con una Geografía que responda a las necesidades de los sujetos, como centro de reflexión geográfica. A través de los escritos autobiográficos se pueden comprender las relaciones de los sujetos con su contexto y de este modo, articular la trama de relaciones que construyen una territorialidad traumática como las abordadas en los diferentes capítulos.

La escritura en formato literario de experiencias de vida de sujetos anónimos, nos acerca a la literatura realista y posibilita a los geógrafos la comprensión de realidades complejas. Abordar la investigación y también la enseñanza de estas problemáticas con los aportes de las biografías contribuye a dar voz a los sujetos invisibles que vivieron procesos traumáticos. La educación es la herramienta fundamental para formar ciudadanos libres, democráticos, respetuosos de las diferencias y que promuevan la paz.

La pedagogía problematizadora pone en juego los diferentes intereses y poderes comprometidos en la conformación de los contextos políticos, sociales y culturales que conforman las herramientas analíticas de la comprensión del territorio. El diálogo de la Geografía con los testimonios contribuye a la reflexión para transitar nuevas estrategias de comprensión de los procesos genocidas. La memoria colectiva es reconstrucción del pasado gobernada por los imperativos del presente.

Construcción social de lugares de memoria. La memoria se inscribe en una materialidad, un espacio y lugares específicos donde se reconocen las identidades de los procesos traumáticos de la sociedad. Desde este punto de vista, la memoria es necesariamente plural, multiforme, y se inscribe en la multiplicidad de tiempos sociales y espacios diferenciados de los cuales se apropian los grupos (Lavabre, 2007). Los individuos son los que recuerdan y no los grupos sociales ni las instituciones, pero los recuerdos y la reconstrucción del pasado se dan en el marco de un grupo y de un contexto localizado temporal y espacialmente.

El tiempo y el espacio cumplen un rol destacado en la construcción y permanencia de la memoria. El tiempo, porque la memoria se sustenta mientras los sujetos la sostienen activamente y el espacio porque la memoria se asocia a imágenes ubicadas en él. Los lugares de memoria se entienden como sitios conformados por prácticas sociales cargadas de significación y simbolismo. Es decir se convierten en productos sociales que materializan aspectos de la cultura, la historia y la política de un territorio. Se crean símbolos y de este modo, se le otorga subjetividad a ciertos espacios. Los dos pilares 
Aportes de la Geografía a la enseñanza de los genocidios y a la construcción de memoria...

sobre los que se construye la memoria son el mental y el simbólico, y de este modo, se convierte a los lugares en enclaves territoriales.

Los lugares de memoria suponen la implementación de políticas públicas, es decir prácticas de construcción de la memoria colectiva. Cuando esas políticas se concretan y se hace visible el uso en el pasado de ese sitio y la carga de simbolismo que presentan, se produce una marcación territorial. Esas marcas territoriales se visibilizan a partir de acciones concretas y reconvierten el sitio a partir de políticas, materializan la memoria en monumentos, placas recordatorias, museos, resignificación de espacios reveladores del pasado de esa comunidad.

Los objetos que se eligen para rememorar el pasado crean relaciones sociales en el presente, es decir el presente convoca el pasado y se materializa en el territorio. Objetos que se convierten en espacio y que tienen el poder de articular pasado, presente y futuro a través de su materialización. De este modo construyen historia pública y las decisiones respecto a la gestión de esos espacios, los convierten a su vez en objetos en disputa por los diferentes grupos. Unos los consideran auténticos espacios de memoria y otros, solo los consideran símbolos del pasado. Para los investigadores y los profesores acceder, visibilizar y convertir estas huellas del pasado en presente con palabras y recuperar las ausencias es un compromiso pedagógico con la construcción de la memoria colectiva.

La perspectiva de género y su relación con la construcción de la memoria. A lo largo de la investigación se desprende una línea de análisis que se enmarca en los estudios desde la perspectiva de género y memoria. Las experiencias violentas y traumáticas que vivieron mujeres, niños, niñas y también varones, se constituyen en objeto de estudio de la construcción memoria colectiva y del enfoque de género. Ambos campos se enriquecen mutuamente con los aportes conceptuales que estimulan el diálogo y la reflexión a partir de la articulación de las dos perspectivas. La noción de género se analiza desde una mirada intersectorial ya que se contextualiza con otras categorías como dominación, etnicidad, diferencias, entre otras. El avance presentado en esta investigación requiere de una profundización en el análisis de la articulación de género y memoria como aporte a la interpretación de la construcción de territorialidades marcadas por las relaciones desiguales de poder entre los sujetos.

En esta línea se propone reflexionar acerca de las violencias sexuales en contextos estratégicos y como proyectos de disputas territoriales. Asimismo, otras violencias extremas, tal como la esclavización de niñas y niños para acciones bélicas complementan la mirada de género y memoria no solo desde la perspectiva de los derechos humanos sino también desde los derechos de los niños y niñas.

El rol de los profesores en la enseñanza de procesos traumáticos y ejercicio de la memoria. Los profesores de Geografía entrevistados ejercen su actividad profesional en 
diferentes colegios de nivel medio de la ciudad de Santa Rosa, La Pampa. Siete de ellos manifiestan conocer el Programa Educación y Memoria y aplicaron alguna secuencia de enseñanza a partir de los lineamientos propuestos. Sin embargo, si bien el Programa está en vigencia desde el año 2006, dos de los profesores reconocen no estar informados de su existencia. Esto resulta una falencia de diversos actores institucionales. Por un lado, las instituciones educativas que escasamente habilitan la discusión y debate de todos los Programas transversales vigentes propuestos por el Ministerio de Educación. Por otro lado, desde el Estado provincial y nacional, se interpreta que no son suficientes las acciones de capacitación y difusión.

Por su parte, las instituciones responsables de las formación inicial (profesorados) tanto de nivel terciario como universitario, no otorgan en sus planes de estudio la relevancia que requiere el tratamiento académico, tanto teórico como práctico, que merece la enseñanza de la Memoria como eje transversal.

Los docentes reclaman capacitaciones específicas para abordar estas temáticas socialmente relevantes y consolidar su proceso de formación continua. En cuanto a las oportunidades y posibilidades de realizar propuestas de articulación para enseñar procesos traumáticos en el aula, tales como los genocidios, los entrevistados expresan problemas para realizarlas. Destacan este tipo de experiencias como muy positivas y consideran que es necesario planificar de manera articulada entre las asignaturas Geografía, Historia, Construcción de Ciudadanía, y Lengua. Sin embargo, reconocen dificultades institucionales y personales para trabajar propuestas de articulación debido a la organización de los tiempos y los espacios escolares.

El abordaje de las problemáticas territoriales actuales demanda un perfil docente con formación que amplíe la visión de la enseñanza a la búsqueda de nodos interdisciplinarios. Si bien la formación es responsabilidad de las instituciones académicas, el proceso de autoformación y capacitación incumbe a los profesionales de la educación. La actualización docente permanente y la elaboración de materiales didácticos acordes con esta perspectiva educativa, permitirán el estímulo de conocimientos socialmente relevantes para la formación de ciudadanos comprometidos con la realidad. En este sentido, la educación presenta el desafío de reconstruir tramas sociales que fortalezcan la convivencia pacífica y democrática. La estrategia de abordaje interdisciplinario de la enseñanza favorece miradas inclusivas de la sociedad. Los temas transversales se constituyen en el centro de discusión curricular y especialmente en la planificación de la enseñanza. Preocupan a los docentes y exigen a las instituciones educativas de todos los niveles la gestión de espacios y tiempos para el desarrollo de trabajos interdisciplinarios. El diseño de propuestas de enseñanza que contemplen este enfoque se corresponde con las coordenadas de época tanto científicas como sociales. La enseñanza de procesos geohistóricos necesita de la discusión teórica acerca de la relación dialéctica entre la enseñanza disciplinar y el abordaje interdisciplinar. 
Aportes de la Geografía a la enseñanza de los genocidios y a la construcción de memoria...

El amparo normativo habilita la metodología de la interdisciplinariedad para planificar prácticas pedagógicas enmarcadas en dicho enfoque.

\section{CONCLUSIONES}

Esta investigación se construyó sobre la premisa de que la Geografía posee marcos teóricos y estrategias didácticas para abordar los procesos genocidas ocurridos en el siglo XX y en el XXI, y que las normativas educativas y los diseños curriculares orientan posibles itinerarios para la formación de ciudadanos respetuosos de los valores democráticos y sensibles a la construcción de memoria colectiva. La temática es, sin dudas compleja, controvertida y requiere para su estudio del aporte diversas disciplinas. Enseñar los genocidios en las clases de Geografía es una decisión de los profesores. Ellos seleccionan los saberes a enseñar luego de un proceso de análisis e interpretación de la normativa nacional y provincial y del curriculum vigente. De las prácticas pedagógicas que los docentes despliegan depende la formación de los estudiantes en problemas socialmente relevantes, tanto en su comprensión como en la habilidad de descubrir los nuevos problemas que encuentren en sus respectivas vidas. Dar luz a situaciones invisibles o invisibilizadas es un desafío educativo que se considera prioritario para la construcción de futuros democráticos.

El aula se convierte en el lugar adecuado para construir, y reconstruir el contexto histórico, social, político, económico, cultural de tiempos trágicos del siglo XX, es decir para comprender la noción de memoria colectiva. "Las huellas en la memoria escapan a nuestra voluntad y, generalmente, aluden a marcas que otros dejaron en nosotros. El compromiso, en cambio, es siempre una respuesta electiva y voluntaria" (Siede, 2007, p. 138). El estudio de memoriales, monumentos, museos, imágenes entre otros, las voces de las víctimas son parte de la reconstrucción de la memoria del pasado. Voces que se hacen escuchar de diversas maneras. Una de ellas es a través de relatos de vida o pequeños fragmentos de ellas. Algunas se publican en entrevistas en artículos periodísticos, otras en investigaciones y también en videos que se pueden observar en páginas web de museos, de proyectos como los mencionados en este capítulo. Los sobrevivientes cuentan sus vivencias durante los tres meses de las matanzas, así como la manera en que reconstruyeron sus vidas.

El estudio de los territorios desde la mirada de todos los actores sociales que lo integran, posibilita la comprensión y la interpretación de su organización y de las consecuencias de ésta en la vida de los sujetos que los habitan. Esta visión del territorio tiene un contenido geográfico en el que se revalorizan las escalas de análisis y se renuevan conceptos tales como actores sociales, intencionalidades, poder, instituciones, Estado, 
empresas, entre otros. Desde esta mirada, compleja y multidimensional, hoy es preciso analizar y comprender la organización territorial con una perspectiva geohistórica.

En palabras de Roberto Bustos Cara (2019), los debates en la ciencia geográfica se ampliaron, así como la necesidad de profundizar la capacidad teórica, predictiva y su posicionamiento epistemológico por la necesidad de actuar, de participar para ejercer la militancia crítica. Es decir que los geógrafos investigadores y docentes, al elegir un tema de investigación, lo tienen que realizar con el compromiso ético, social, y político que les lleve a involucrase en la problemática convencidos que podrán cambiarla.

En acuerdo con Unwin (1995) las prácticas geográficas han aceptado la diversidad de la disciplina. En este contexto académico, una verdadera Geografía comprometida con las realidades del siglo XXI tiene que intentar comprender las problemáticas que afectan a las sociedades, darlas a conocer, para que se intente su superación. En la práctica esta no es tarea sencilla, sin embargo, a partir de la investigación elaborada en esta tesis se pretende relacionar investigación con enseñanza de la Geografía. Centrar la mirada y hacer foco en problemáticas invisibilizadas para la mayoría de la sociedad, pero que afectan de manera aterradora a otra parte de la misma, estimula la práctica de una Geografía comprometida con los contextos contemporáneos. Investigar y enseñar procesos traumáticos y ponerlos a consideración de la comunidad académica y educativa, es contribuir a construir un mundo con menos desigualdades, carencias, violencias, en síntesis es aportar conocimiento para cimentar una ciudadanía plena de derechos. La geografía tiene mucho por decir.

La complejidad territorial contemporánea impide la visibilidad de realidades que permanecen ocultas. La intención de esta investigación fue develar, dar a conocer y promover el debate de cuestiones que muchas veces la sociedad mira pero no ve. Las estrategias de enseñanza que se desprenden del recorrido de esta tesis, tienen la intención de abrir caminos teóricos y metodológicos para bucear en temas escasamente divulgados y habilitar el abordaje de procesos traumáticos y la construcción de la memoria colectiva. Desde la perspectiva de Nogué, las “(...) geografías de la invisibilidad (aquellas geografías que están sin estar) marcan nuestras coordenadas espaciales y temporales, nuestros espacios existenciales, puede que no más, pero sí tanto como las geografías cartesianas, visibles y cartografiables propias de las lógicas territoriales hegemónicas” (2007, p. 377). Es por ello que la producción del conocimiento geográfico tiene que realizar aportes para la transformación de la sociedad. La utilidad de las investigaciones universitarias derivará en potenciar las posibilidades de pensar estrategias de emancipación para el conjunto de la ciudadanía. La Didáctica de la Geografía tiene ese potencial ya que articula investigación con enseñanza y la consolidación de su institucionalización permite construir saberes para intervenir en la construcción de una representación crítica del mundo. 
El desafío es, entonces, favorecer la apropiación del pasado reciente y el presente por parte de toda la sociedad con el propósito de construir comunidades de memoria que reconozcan que los procesos violentos son responsabilidad de todos los sujetos. En este sentido, quizás el único norte posible es la pedagogía del compromiso de todos los actores sociales, no solo de la escuela como institución, sino de familias, gobiernos, asociaciones civiles, entre otros. Una pedagogía del compromiso con la memoria que estimule la reconstrucción del tejido social, la convivencia en el ámbito de la paz y el respeto por las diferencias, eje central de las políticas públicas de derechos humanos. En este sentido la Universidad Pública tiene la responsabilidad de trabajar para fortalecer la educación como derecho humano y los derechos humanos como contenido de la educación. La formación superior, desde los espacios de enseñanza, investigación y extensión contribuye al fortalecimiento y consolidación de prácticas democráticas. Es decir que los profesionales que egresan de instituciones de altos estudios tienen el compromiso de garantizar el cumplimiento de los derechos y el pleno ejercicio de la ciudadanía.

La Geografía desde la enseñanza tiene mucho que aportar, la relevancia social que tienen las problemáticas que se manifiestan en el territorio, son objeto de estudio y enseñanza de la geografía. Ese es precisamente el sentido que la enseñanza de esta ciencia tiene que tener. Formar a los estudiantes en el conocimiento geográfico les brindará habilidades para interpretar y comprender problemáticas que afectan a la sociedad y de este modo, decidir actuar y convertirse en actores sociales activos para intervenir en ellas. La enseñanza de la Geografía nos permite imaginar otros mundos posibles, tal como propone Capel (2002, p.62): “Al igual que Borges, los geógrafos debemos construir geografías, fabular arquitecturas, proponer mundos alternativos. Y tal vez también pensar en la forma de encontrar el hilo para ayudar a la gente a orientarse en el laberinto del universo (...)”. Este es el camino que inicié en esta investigación, la cual me brindó la posibilidad de conocer y descubrir geografías ocultas, es por ello que asumo el compromiso de difundir la investigación y la enseñanza de la geografía ya que la considero una herramienta poderosa y a su vez estratégica para promover la formación en ciudadanía.

\section{REFERENCIAS BIBLIOGRÁFICAS}

Arfuch, L. (2014). (Auto) biografía, memoria e historia. Clepsidra. Revista Interdisciplinaria de Estudios sobre Memoria, 1, 68-81.

Benejam, P. (1999). La oportunidad de identificar conceptos clave que guíen la propuesta curricular de Ciencias Sociales. Revista Iber, Didáctica de las Ciencias Sociales. Geografía e Historia, 21, 5-12. 
Benejam, P. (2001). Los contenidos de la didáctica de las Ciencias Sociales en la formación del Profesorado. En Arrondo, C. y Bembo, S. (Comp.) (2001). La formación docente en el Profesorado de Historia. Rosario: Homo Sapiens.

Bolívar, A. (2002). “¿De nobis ipsis silemus?”: Epistemología de la investigación biográfico-narrativa en educación. Revista Electrónica de Investigación Educativa, 4(1), 1-26. Recuperado de: http://redie.uabc.mx/redie/article/viewFile/49/91

Bréville, B. (2016). Atlas de historia crítica y comparada. Una visión heterodoxa desde la revolución Industrial hasta hoy. Buenos Aires: Capital Intelectual.

Bruneteau, B. (2009). El siglo de los genocidios. Madrid: Alianza Editorial.

Bustos Cara, R. (2019). A 25 años de la Institucionalización del Doctorado en Geografía en la UNS: Profesionalización, pensamiento reflexivo y militancia crítica. Conferencia Inaugural de las VI Jornadas del Programa de Posgrado del departamento de Geografía y Turismo. Bahía Blanca: UNS.

Camilloni, A. y otros (1996). Corrientes didácticas contemporáneas. Buenos Aires: Paidós.

Capel, H. (2002). Borges y la Geografía del siglo XXI. San Juan: FFHA.

Declaración Universal de los Derechos Humanos. (1948). Recuperado de: https://www. ohchr.org/en/udhr/documents/udhr translations/spn.pdf

Dussel, I. (2001). La Trasmisión de la historia reciente. Reflexiones pedagógicas sobre el arte de la memoria. En Guelerman, S. (comp) Memorias en Presente. Identidad y Transmisión en la Argentina posgenocidio. Buenos Aires: Editorial Norma.

Eco, U. (2015). Las funciones de las Universidades en la actualidad. En Di Liscia M. S. (comp.) Umberto Eco y MassimoVedobelli en conferencia. Santa Rosa: EdUNLPam.

Estepa Giménez, J. (2009). Aportaciones y retos de la investigación en la didáctica de las Ciencias Sociales. Investigación en la escuela, 69, 19-30.

Fernández Caso, M. V. y Gurevich, R. (Directoras). (2014). Didáctica de la Geografía. Prácticas Escolares y formación de profesores. Buenos Aires: Biblos.

Giroux, H. (1990). Introducción a los profesores como intelectuales. En Los profesores como intelectuales. Hacia una pedagogía crítica de los aprendizajes. Barcelona: Paidós.

González Valencia, G. A. y Santisteban Fernández, A. (2014). Una Mirada a La Investigación en Didáctica de Las Ciencias Sociales. Revista Latinoamericana de Estudios Educativos, 10, Enero-Junio, 7-17. Disponible en:http://www.redalyc. org/articulo.oa?id=134139791001 
Aportes de la Geografía a la enseñanza de los genocidios y a la construcción de memoria...

Henríquez, R y Pagés. J. (2004). La investigación en didáctica de la Historia. Revista Educación XXI, 7, 63-83. Recuperado de: http://revistas.uned.es/index.php/ educacionXX1/article/view/330/286

Hernández Cardona, F. X. (2000). Epistemología y diversidad estratégica en la didáctica de las ciencias sociales. Iber, Didáctica de las Ciencias Sociales Geografía e Historia, 24, 19-31.

Hessel, S. (2011). ¡Indígnate!. Buenos Aires: Destino.

Jelin, E. (2002). Los trabajos de la Memoria. Madrid: Siglo XXI.

Jelin, E y Langland, V. (comp.) (2003). Monumentos, memoriales y marcas territoriales. Buenos Aires: Siglo XXI.

Kemmis, S. (1993). Hacia una teoría crítica del curriculum. En El curriculum más allá de la reproducción. Madrid: Morata.

Latorre, A. (2003). La investigación acción. Conocer y cambiar la práctica Educativa. Barcelona: Editorial Graó.

Lavabre, M.C. (2007). Maurice Halbwachs y la sociología de la memoria. En Anne Pérotin-Dumon (dir) Historizar el pasado vivo en América Latina.

Le Roux, A. (2005). La formación del profesorado en didáctica de la Geografía: ¿Cómo articular investigación y formación? El contexto francés. Revista Enseñanza de las ciencias Sociales, 4, 105-116.

Leach, P. (2003). Rwanda: para deconstruir un Genocidio "Evitable". Estudios de Asia y África XXXVIII: 2, 321-344.

Levstick, L.S. y Tyson, C.A. (Eds) (2008). Handbook of Research in Social Studies Education. New York/London:Routledge.

Ley De Educación Nacional $\mathrm{N}^{\circ}$ 26.206. (2006). Recuperado de: https://www. fmmeducacion.com.ar/wp-content/uploads/2018/03/Ley-26026-de-EducacionNacional.pdf.

Nogué, J. (ed.). (2007). La construcción social del paisaje. Madrid: Biblioteca Nueva.

Membrado, Z. (2019). Último asesinato del genocidio en Ruanda. Recuperado de: https://www.elmundo.es/cronica/2019/04/07/5ca7b39521efa0a1228b45c8.html.

Ministerio de Educación de la Nación. (2006). Programa "Educación y Memoria". Recuperado de: http://www.me.gov.ar/educacionymemoria/

Ministerio de Educación de la Nación. (2012). NAP para Ciencias Sociales, Historia, Geografía y Economía. Resolución No 180/12.

Ministerio de Educación de La Pampa (2013). Materiales Curriculares para el Ciclo Orientado. 
Ministerio de Educación de La Pampa. (2018). Programa educación y Memoria. Disponible en: https://sitio.lapampa.edu.ar/index.php/educacion-y-memoria.

ODS (2016). https://www.un.org/sustainabledevelopment/es/

Ortega Valcárcel, J. (2004). La geografía para el siglo XXI. En Romero, J. (coord.) (2004) Geografía Humana. Procesos, riesgos e incertidumbres en un mundo globalizado. Barcelona: Ariel.

Oslender, U (2018). Terror y geografía: examinar múltiples espacialidades en un mundo "aterrorizado". Clepsidra. Revista interdisciplinaria de Estudios sobre Memoria, 5(9), 68-85. Disponible en: http://ppct.caicyt.gov.ar/index.php/clepsidra/article/ view/OSLENDER

Ripa, L. (2014). Algo de filosofía y educación en derechos humanos. Revista de Ciencias Sociales, 25. Universidad Nacional de Quilmes.

Rosemberg, J. y Kovacic, V. (2010). Educación, Memoria y derechos Humanos: orientaciones pedagógicas y recomendaciones para su enseñanza. Buenos Aires: Ministerio de Educación de la Nación.

Sant, E. (2018). La educación para la ciudadanía global como base de la educación política: Sí! Pero.... En Breogán, T, Santisteban, A y Pagés, J (2018). Què està passant al món? Què estem ensenyant? Universitat Autònoma de Barcelona. Per un ensenyament de les ciències socials centrat en els problemes, la justícia social i la ciutadania global (pp. 27-32). Barcelona: GREDICS.

Santisteban Fernández, A. (2019). La enseñanza de las Ciencias Sociales a partir de problemas sociales o temas controvertidos: estado de la cuestión y resultados de una investigación. El Futuro del Pasado, 10, 57-79. http://dx.doi.org/10.14516/ fdp.2019.010.001.002

Shaw, M. (2013). ¿Qué es el genocidio? Buenos Aires: Prometeo.

Siede, I. (2017). Vaivenes y claroscuros de la enseñanza de los derechos humanos en Argentina. Revista Latinoamericana de Derechos Humanos, 28(1), 87-115. http:// dx.doi.org/10.15359/rldh.28-1.4

Souto González, X. M. (2013). Investigación e Innovación Educativa: el caso de la Geografía escolar. Scripta Nova. Revista Electrónica de Geografía y Ciencias Sociales, XVII (459), 1-36. Disponible en: http://www.ub.edu/geocrit/sn/sn-459.htm

Thémines, J. F. (2009). Investigación y formación del profesorado en didáctica de la geografía: posibilidades e implicaciones de algunas investigaciones en las prácticas docentes en Francia. Revista Enseñanza de las Ciencias Sociales. Revista de Investigación, 8, 13-23. Recuperado de: www.raco.cat/index.php/EnsenanzaCS/ article/view/184402 
Traverso, E. (2016). La historia como campo de batalla. Interpretar las violencias del siglo XX. Buenos Aires: Fondo de Cultura Económica.

Tutiaux-Guillon, N. (2003). Los fundamentos de una investigación sobre la concepción de las finalidades cívicas y culturales del profesorado de Geografía e Historia. Objetivo de esta etapa. Revista Enseñanza de las Ciencias Sociales, 2, 27-35.

Tutiaux-Guillon, N. (2011). Les quiestions socialment vives, un repte per a la història i la geografia escolars? En J. Pagès y A. Santisteban (coords.), Les qüestions socialment vives i l'ensenyament de les ciències socials (pp. 25-39). Barcelona: Publicacions de la UAB.

UGI. (2016). Declaración Internacional sobre la educación Geográfica. Recuperado de: http://www.igu-cge.org/wp-content/uploads/2018/02/IGU 2016 spanish1.pdf

UNESCO. (2016). Educación para la Ciudadanía Mundial. Preparar a los educandos para los desafios del siglo XXI. Paris: UNESCO: Disponible en: https://unesdoc. unesco.org/ark:/48223/pf0000244957.

Unwin, T. (1995). El Lugar de la Geografía. Madrid: Cátedra.

Varela, B. (2009). Geografías de la Memoria. Lugares, Desarraigos y reconstitución identitaria en Situación de Genocidio. La Plata: Editorial de la Universidad de La Plata.

Wabgou, M. (2013). Experiencias posconflicto de países africanos: justicia transicional en Ruanda. NOVUM JUS, 7(1), 31-49. 